\section{Is ethics failing to keep up with scientific advances?}

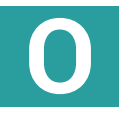

ur recent Spotlight on CRISPR, along with our news coverage of the creation of the first human-monkey chimera, raised interesting ethical questions. How long should a CRISPR-edited embryo be allowed to develop for? What about a chimera? Is editing 'normal' traits acceptable? These are all questions that have been raised and according to our survey at least - remain unanswered, which suggests that our continuing advances in scientific abilities is outpacing what we feel comfortable with morally.

With ethical issues also being raised by advances in Al, data analytics and synthetic biology, its clear that our increasing technical abilities need to come hand-in-hand with increased ethical oversight. This is happening to an extent - new ethics bodies are cropping up; for example, China has recently announced a plan to establish a national science and technology ethics committee, and the WHO has announced an advisory committee to develop global standards for genome editing.

However, these two committees at least feel somewhat like reactions to questionable research already performed - is there a way to proactively prevent research overstepping the ethical mark in the future without having a negative effect on advancement? Would something akin to the Hippocratic Oath - currently taken by physicians to ensure ethical practices work if applied to those in the life sciences? Food for thought.

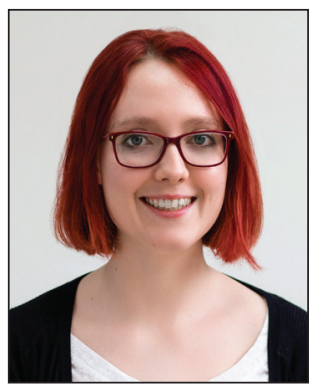

\section{Francesca Lake}

Editor in Chief, Future Science Group, Unitec House, 2 Albert Place, London, UK. f.lake@future-science.com
BioTechniques is a peer-reviewed journal dedicated to the publication of original laboratory methods, related technical tools, and methods-oriented review articles that are of broad interest to scientists engaged in basic applied life science research. Complete Instructions for Authors are available at: https://mc04.manuscriptcentral. com/fs-btn, BioTechniques' website for online manuscript submission. All manuscripts should be submitted at this site.

\section{BioTechniques Staff}

Editorial, Production \& Circulation

Chairman: James Drake

Managing Director. Phil Garner

Publisher. Sarah Mayes

Editor in Chief: Francesca Lake

Managing Editor. Joseph Martin

Digital Editor: Abigail Sawyer

Head of Production: Zara Robinson

Sales \& Business Offices

Advertising: JT Hroncich • jt@biotechniques.com

Subscriptions: Dominik March • d.march@future-science.com

Reprints: Sam Cavana • s.cavana@future-science.com

List Rental: Leela Ripton • I.ripton@future-science.com

Permissions:Adriana Gonzalez•a.gonzalez@future-science.com

\section{Editorial Board}

Bill Brizzard, Indiana University Research and

Technology Corp.

Bruce Budowle, UNT Health Science Center

Piotr Chomczynski, Molecular Research Center

Rita R. Colwell, University of Maryland-College Park and Johns Hopkins University

Joshua J. Coon, University of Wisconsin-Madison

David Cronk, Charles River Laboratories

Manel Esteller, Spanish National Cancer Centre (CNIO)

Jeffrey Felton, Western University of Health Sciences

Erica A. Golemis, Fox Chase Cancer Center

Peter M. Gresshoff, The University of Queensland

Yoshihide Hayashizaki, RIKEN

Jörg Hoheisel, German Cancer Research Center

Pui-Yan Kwok, University of California, San Francisco

Rachael L. Neve, Massachusetts Institute of Technology

Peter J. Oefner, University of Regensburg

Stephen W. Paddock, University of Wisconsin-Madison

Scott D. Patterson, Gilead Sciences, Inc.

Leonard F. Peruski, Jr., Centers for Disease Control

George Poste, Arizona State University

John Quackenbush, Harvard School of Public Health

Joshua Rappoport, Northwestern University School of Medicine

John Rossi, City of Hope

Michel Goedert, MRC

Herbert P. Schweizer, Colorado State University

Barton Slatko, New England Biolabs

Steve S. Sommer, MEDomics, LLC

Igor Stagljar, University of Toronto

Mathias Uhlén, The Royal Institute of Technology

Timothy Veenstra, SAIC-Frederick, Inc.

Kent E. Vrana, Penn State College of Medicine

Michael Weiner, AxioMx 